Washington University School of Medicine Digital Commons@Becker

3-1-2021

\title{
Not all lymphoid aggregates in chronic lymphocytic leukemia (CLL) patients are due to CLL!
}

Lily Mahapatra

Washington University School of Medicine in St. Louis

Tianjiao Wang

Washington University School of Medicine in St. Louis

Yi-Shan Lee

Washington University School of Medicine in St. Louis

John L Frater

Washington University School of Medicine in St. Louis

Follow this and additional works at: https://digitalcommons.wustl.edu/open_access_pubs Please let us know how this document benefits you.

\section{Recommended Citation}

Mahapatra, Lily; Wang, Tianjiao; Lee, Yi-Shan; and Frater, John L, "Not all lymphoid aggregates in chronic lymphocytic leukemia (CLL) patients are due to CLL!." Clinical Case Reports. 9, 3. 1785 - 1786. (2021). https://digitalcommons.wustl.edu/open_access_pubs/11235

This Open Access Publication is brought to you for free and open access by Digital Commons@Becker. It has been accepted for inclusion in Open Access Publications by an authorized administrator of Digital Commons@Becker. For more information, please contact vanam@wustl.edu. 


\title{
Not all lymphoid aggregates in chronic lymphocytic leukemia (CLL) patients are due to CLL!
}

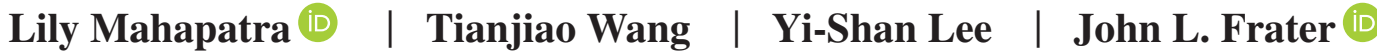

Department of Pathology and Immunology, Washington University School of Medicine, St. Louis, MO, USA

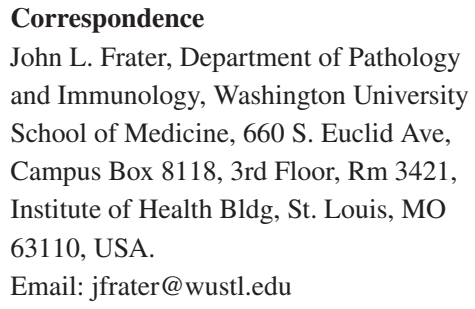

\begin{abstract}
Infection is a common cause of morbidity and mortality in chronic lymphocytic leukemia and should be considered when examining bone marrow specimens to identify a potentially treatable pathogen.
\end{abstract}

\section{K E Y W O R D S}

Anaplasma, chronic lymphocytic leukemia, Ehrlichia, ehrlichiosis, tick borne illness
A 75-year-old man with a history of chronic lymphocytic leukemia (CLL) diagnosed in 2015 and currently treated with ibrutinib presented to the emergency department with a 1-month history of malaise and generalized fatigue. The patient denied any recent travel history and had no known sick contacts. A computed tomography scan showed hepatosplenomegaly and extensive lymphadenopathy. A complete blood count showed bicytopenia; white blood cell count, $7.8 \times 10^{9} / \mathrm{L}$; hemoglobin, $12.3 \mathrm{~g} / \mathrm{dL}$; platelets, $39 \times 10^{9} / \mathrm{L}$. Additional laboratory findings included elevated liver enzymes: AST, $81 \mathrm{U} / \mathrm{L}$; ALT, $72 \mathrm{U} / \mathrm{L}$; and elevated alkaline phosphatase, $353 \mathrm{U} / \mathrm{L}$.

Given the patient's past medical history of CLL, a bone marrow biopsy was performed and showed hypercellular marrow with multiple lymphohistiocytic aggregates (Figure 1A) that mimicked CLL. However, the aggregates were predominately composed of $\mathrm{T}$ cells rather than $\mathrm{B}$ cells, highlighted by CD3 and CD20 staining (Figure 1B,C), favoring a reactive process. Flow cytometry demonstrated low-level involvement by CLL, with approximately $3 \%$ monoclonal, kappa-restricted B lymphocytes (Figure 1D). Review of the bone marrow aspirate showed myeloid precursors with intracellular morulae (Figure 1E) and ehrlichiosis was confirmed by detection of Ehrlichia species DNA by polymerase chain reaction. Morulae were not identified in the patient's peripheral blood smear; however, it has been documented that morulae can be seen in only $22 \%$ to $38 \%$ of peripheral blood smears from ehrlichiosis patients. ${ }^{1,2}$ Upon further discussion, the patient disclosed that he recently hiked in the woods of rural Missouri and received numerous tick bites. The patient was treated with doxycycline $100 \mathrm{mg}$ two times per day for 10 days and clinically improved.

There have been very few reports of bone marrow findings in patients with ehrlichiosis, but lymphohistiocytic aggregates have been described. ${ }^{2}$ This unique case highlights the importance of laboratory testing supported by a thorough clinical history to ensure accurate diagnosis.

\section{CONFLICT OF INTEREST}

None declared.

\section{AUTHOR CONTRIBUTIONS}

LM: wrote the manuscript. TW: acquired data. Y-SL: analyzed and interpreted data. JLF: analyzed and interpreted data and wrote the manuscript.

\section{ETHICAL APPROVAL}

The manuscript was published with written consent of the patient. The manuscript complies with the ethical approval requirements.

This is an open access article under the terms of the Creative Commons Attribution License, which permits use, distribution and reproduction in any medium, provided the original 

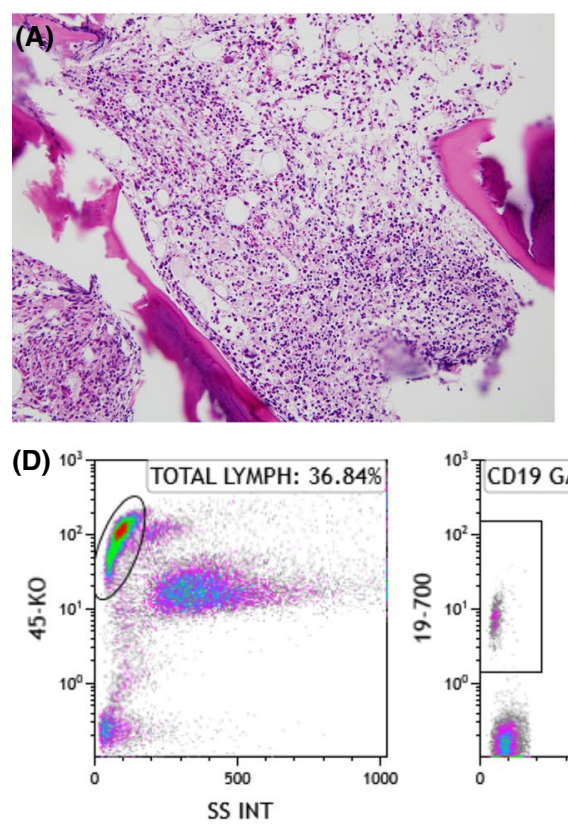

(B)

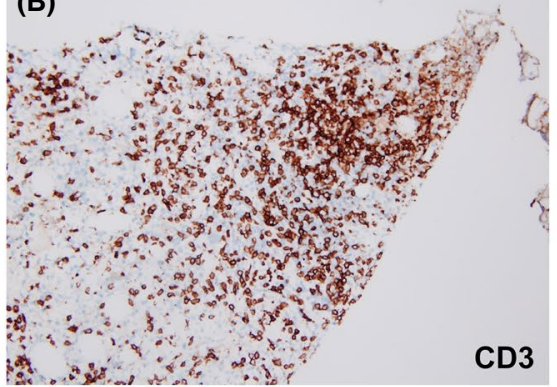

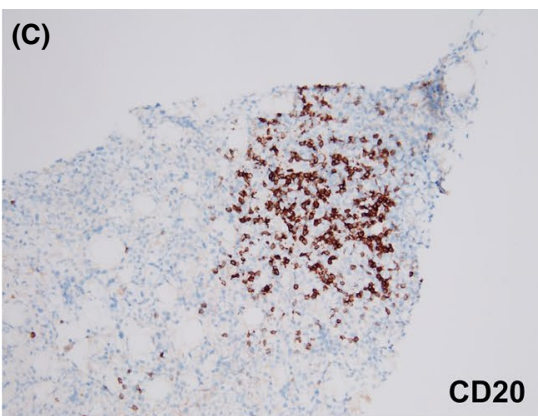

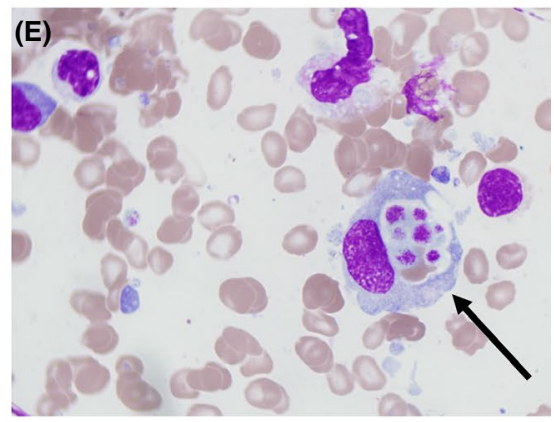

F I G U RE 1 A, Bone marrow trephine biopsy showing lymphohistiocytic aggregate (hematoxylin and eosin, original magnification $\times 400$ ). Immunohistochemistry demonstrating admixed CD3 (B) and CD20 (C) positive lymphocytes in the aggregate. D, Flow cytometric analysis of the bone marrow aspirate revealed a monoclonal B-cell population comprising $~ 3 \%$ of specimen cellularity (E) Review of the bone marrow aspirate revealed morulae of Ehrlichia organisms in granulocyte precursors

\section{DATA AVAILABILITY STATEMENT}

The data that support this study are available from the corresponding author upon reasonable request.

\section{ORCID}

Lily Mahapatra (D) https://orcid.org/0000-0001-6133-9823

John L. Frater (iD https://orcid.org/0000-0002-4614-681X

\section{REFERENCES}

1. Hamilton KS, Standaert SM, Kinney MC. Characteristic peripheral blood findings in human ehrlichiosis. Mod Pathol. 2004;17:512-517.
2. Allen MB, Pritt BS, Sloan LM, et al. First reported case of Ehrlichia ewingii involving human bone marrow. J Clin Microbiol. 2014;52(11):4102-4104.

How to cite this article: Mahapatra L, Wang T, Lee Y-S, Frater JL. Not all lymphoid aggregates in chronic lymphocytic leukemia (CLL) patients are due to CLL!. Clin Case Rep. 2021;9:1785-1786. https://doi. org/10.1002/ccr3.3701 